Article

\title{
The UN 2030 Agenda and the Quest for Policy Integration: A Literature Review
}

\author{
Basil Bornemann ${ }^{1, *}$ and Sabine Weiland ${ }^{2}$ \\ ${ }^{1}$ Sustainability Research Group, Department of Social Sciences, University of Basel, 4056 Basel, Switzerland; \\ E-Mail: basil.bornemann@unibas.ch \\ 2 European School of Political and Social Sciences, Université Catholique de Lille, 59000 Lille, France; \\ E-Mail: sabine.weiland@univ-catholille.fr \\ * Corresponding author
}

Submitted: 15 September 2020 | Accepted: 18 December 2020 | Published: 26 February 2021

\begin{abstract}
The adoption of the UN 2030 Agenda and the Sustainable Development Goals (SDGs) represents a milestone in international sustainability politics. The broad and ambitious agenda calls for a reconsideration of established principles and practices of sustainability governance. This article examines how the 2030 Agenda changes the notion of policy integration, which represents a fundamental principle of sustainability governance. In general, policy integration denotes forms of cross-cutting policymaking to address the complexity of real-world problems. In the context of the sustainability discourse, the concept has long been interpreted as environmental policy integration, referring to the integration of environmental concerns into other sectoral policies. Based on a review of the current SDG literature, we examine whether and how this interpretation has changed. In so doing, the reasons (why?), objects (what?) and modes (how?) of policy integration in the context of the 2030 Agenda are specified. The analysis reveals that the 2030 Agenda promotes a comprehensive, reciprocal, and complex form of goal integration which differs markedly from environmental policy integration. This novel understanding of policy integration for sustainable development calls for future research on its impact and relevance in political practice.
\end{abstract}

\section{Keywords}

2030 Agenda; environment; policy integration; SDGs; sustainability governance

\section{Issue}

This article is part of the issue "The 2030 Agenda for Sustainable Development: Transformative Change through Sustainable Development Goals?" edited by Thomas Hickmann (University of Utrecht, The Netherlands), Markus Lederer (Technical University of Darmstadt, Germany), Jens Marquardt (Technical University of Darmstadt, Germany), Sandra Schwindenhammer (Justus Liebig University Giessen, Germany) and Sabine Weiland (Catholic University of Lille, France).

(C) 2021 by the authors; licensee Cogitatio (Lisbon, Portugal). This article is licensed under a Creative Commons Attribution 4.0 International License (CC BY).

\section{Introduction}

The adoption of the 2030 Agenda and the Sustainable Development Goals (SDGs) by the UN General Assembly in 2015 represents a milestone in international sustainability governance. For the first time in history, the international community of states has agreed on a comprehensive, binding, and relatively concrete system of goals and targets to guide the major global transformation towards sustainability (Biermann, Kanie, \& Kim, 2017).
Ground-breaking and unprecedented in its scope, the 2030 Agenda poses major governance challenges. This is reflected, among others, in a shift from a rule-based mode of governance to a novel approach of governance through goal setting (Biermann et al., 2017; Kanie \& Biermann, 2017; Kanie et al., 2019). Apart from changes in the global governance architecture, the 2030 Agenda also brings about shifts at the level of basic governance orientations (Bowen et al., 2017). While still in the tradition of the global sustainability discourse in normative 
and conceptual terms, the 2030 Agenda representswe argue-a transformational moment for established sustainability thinking and practice. It questions, problematises, and reinterprets existing assumptions, interpretations, and normativities of sustainability as well as approaches and practices of sustainability governance (Langford, 2016; Meadowcroft et al., 2019).

In this article, we substantiate this claim by analysing how the 2030 Agenda brings about changes in the interpretation of policy integration, which represents a long-standing key principle of sustainability governance. Sustainability problems transcend existing institutionalised areas, or 'silos,' of policymaking and call for approaches and strategies of integrative, cross-cutting policymaking (Bornemann, 2014; Liberatore, 1997; Steurer, 2010). Integration has always been a core element of sustainability thinking and governance, and it is also of central importance for the 2030 Agenda (Le Blanc, 2015; Nilsson \& Persson, 2017). In line with Boas, Biermann, and Kanie (2016), we argue that the 2030 Agenda has specific implications for the interpretation of policy integration that warrant further conceptual investigation. This article will carry out such an investigation through a literature review. We reconstruct the notion of policy integration promoted in key texts that have shaped, and continue to shape, the debate on policy integration in the context of the 2030 Agenda. This conceptual exploration is meant to provide the ground for more focused empirical analyses as well as more targeted practices to realise policy integration for the 2030 Agenda 'on the ground.'

We begin with a recapitulation of the general concept of policy integration and its meaning and relevance in sustainability discourse (Section 2). We then present the literature review method and the three guiding questions that allowed us to decipher the understanding of policy integration present in the literature (Section 3 ). Next, we summarise the results of our analysis of the key texts and specify the meaning of policy integration in the context of the 2030 Agenda (Section 4). In the discussion, we interpret that meaning in relation to earlier concepts of sustainability-oriented policy integration (Section 5). We conclude with an outlook on future research on the impact and relevance of the policy integration conception in political practice (Section 6).

\section{Background: Policy Integration and Sustainable Development}

\subsection{Policy Integration in Policy Research}

Policymaking has traditionally been carried out in distinct, institutionalised policy sectors, with specific responsibilities and using specialised policies (Burstein, 1991; Jochim \& May, 2010). With its focus on specialised knowledge and the division of responsibilities, this approach to policymaking generally reflects the modernist notion of a functionally differentiated society- and as such has led to the emergence of a 'sectoral view' in current policy research (Jochim \& May, 2010). While the 'siloing' of public policy has been a dominant trend in all policy areas in recent decades, there are also counter-movements that have emerged in response to the increasing differentiation of political systems (Bornemann, 2016; Christensen \& Lægreid, 2007).

Given the growing complexity and 'wickedness' of policy problems (Termeer, Dewulf, Breeman, \& Stiller, 2015), as well as the emergence of ideas for the transformation of society, such as sustainable development (Meadowcroft, 2013), policymakers are increasingly opting for integrative approaches to policymaking (Bornemann, 2014; Rayner \& Howlett, 2009). Many policy problems are inter-sectorial, meaning they cut across policy domains, governance levels, and established jurisdictions (Candel \& Biesbroek, 2016). Climate policy, for example, would fall short if it only relied on climate action and did not include measures in adjacent policy areas, such as agriculture, economy, transport, or energy (Adelle \& Russel, 2013). These efforts to organise the 'policy mess' and deal with complex problems cutting across established policy fields more comprehensively come to bear in comprehensive and integrative political strategies, such as climate adaptation or sustainability strategies (Casado-Asensio \& Steurer, 2014; Meadowcroft, 2007; Nordbeck \& Steurer, 2015; Steurer, 2008).

Several partially overlapping and sometimes synonymously used concepts have been promoted in policy analysis to study practices of integrative or cross-cutting policymaking (Cejudo \& Michel, 2017; Tosun \& Lang, 2017). These include, among others, policy coordination (Peters, 1998), policy coherence (OECD, 2018), whole-ofgovernment (Christensen \& Lægreid, 2007), joined-up government (Bogdanor, 2005), and holistic governance (6, Leat, Seltzer, \& Stoker, 2002). Most comprehensively, the issue has been addressed as 'policy integration' (Bornemann, 2014; Briassoulis, 2005; Cejudo \& Michel, 2017; Jordan \& Lenschow, 2008; Lenschow, 2002a; Nilsson \& Eckerberg, 2007; Nilsson, Eckerberg, Hagberg, Swartling, \& Söderberg, 2007; Underdal, 1980). The latter term refers to attempts to combine different policy areas with specific, relatively stable problem configurations, goals and measures, as well as actor constellations and institutions, into a more comprehensive and coordinated policy of one kind or another.

\subsection{Policy Integration in the Context of Sustainability Thinking}

The concept of sustainable development, most prominently expressed in the Brundtland Report and subsequently institutionalised in the 'Rio process,' requires the systematic connection of the seemingly incompatible goals of economic competitiveness, social development, and environmental protection. It emerged against the background of a perceived need to bring together 
environmental and development issues that had previously only been discussed separately on the international scene. Whereas growth and development had been seen as coming at the expense of environmental protection, the Brundtland Report highlighted the inherent connections between the two (WCED, 1987). Sustainable development is essentially a critique of the dominant industrial development model (Dryzek, 2013) which is reaching its limits, as evidenced by both the wealthrelated environmental destruction of the Global North and the poverty-related environmental destruction of the Global South. These can no longer be perceived as singular problems but as part of a global crisis of the industrial development model itself (Brand, 2017; Purvis, Mao, \& Robinson, 2019). Sustainable development aims to secure the development options for present and future generations while simultaneously preserving the natural systems on which our lives depend (Jacobs, 1999). Given the interdependencies and interconnections between different systems, spaces, and temporal horizons, policy integration became a central concept in sustainability-oriented governance (Bornemann, 2014). To be able to tackle the interconnected nature of sustainability problems, the existing fragmentation of policy systems has to be overcome and replaced by more integrated forms of policymaking.

In the context of the discourse on sustainable development, however, one particular interpretation of policy integration became dominant: The integration challenge associated with sustainability was conceived primarily in terms of environmental policy integration (EPI; Jordan \& Lenschow, 2010; Lenschow, 2002a; Liberatore, 1997). Liberatore (1997), for example, identifies a 'straightforward' relationship between EPI and sustainable development, stating that:

If environmental factors are not taken into consideration in the formulation and implementation of the policies that regulate economic activities and other forms of social organisation, a new mode of development that can be environmentally and socially sustained in the long term cannot be achieved. (p. 107)

The close link has also been emphasised in the political realm. In the EU, for example, EPI was institutionalised in article 6 of the Amsterdam Treaty according to which "environmental considerations should be integrated into other policies in order to deliver sustainable development" (as cited in Lenschow, 2002b, p. 14). From 1998 onwards, EPI has moved centre stage in the so-called 'Cardiff process' which aims at integrating environmental issues in sectoral policies of the Union.

Jordan and Lenschow (2010) distinguish stronger (i.e., pro-environment) and weaker understandings of EPI. As part of the latter reading, EPI is largely understood as policy coordination, which implies a focus on comprehensiveness, aggregation and consistency of action. The rationale of EPI is that genuine sustainable devel- opment can only be achieved if the environment is no longer treated as a separate sector in policymaking with its own actors, organisations, and institutions. Rather, environmental perspectives must become an integral part of the goals, strategies, and policymaking procedures of all public policy sectors, such as energy, agriculture, and transport, as well as of central government bodies, e.g., the economic and finance ministries, where many key policy decisions are taken (Nilsson, Pallemaerts, \& Homeyer, 2009).

The stronger, more normative readings of EPI include the conception of Lafferty and Hovden (2003) who define the environment as a principled standard for policymaking in all sectors. According to them:

Environmental policy integration implies the incorporation of environmental objectives into all stages of policymaking in non-environmental policy sectors, with a specific recognition of this goal as a guiding principle for the planning and execution of policy; accompanied by an attempt to aggregate presumed environmental consequences into an overall evaluation of policy, and a commitment to minimise contradictions between environmental and sectoral policies by giving principled priority to the former over the latter. (Lafferty \& Hovden, 2003, p. 15, emphasis added)

This normative definition of EPI goes beyond more general interpretations of policy integration in that it aims precisely not to balance different objectives - rather, the environment should be a principled priority of any policy. As Lafferty and Hovden (2003) write:

Most discussions of EPI assume either that the environmental and non-environmental objectives should be balanced....We would argue that the whole point of $E P I$ is, at the very least, to avoid situations where environmental objectives become subsidiary; and in the view of sustainable development, to ensure that they become principal or overarching societal objectives. This is arguably the essential difference between 'environmental policy integration' and 'policy integration' conceived more generally. (p. 15)

In this perspective, EPI refers to a unidirectional integration of environmental concerns into other policy sectors. Moreover, EPI should be interpreted as an asymmetric integration task geared towards a revision of the traditional hierarchy of policy objectives which prioritises economic issues and neglects environmental concerns and values.

While the ambitious notion of a principled prioritisation, as suggested by Lafferty and Hovden (2003), remained contested and did not translate into a widespread practice of policy integration, EPI more generally, understood as the unidirectional incorporation of environmental goals into sectoral policies, has long dominated how policy integration was framed in the context 
of sustainable development. Whenever calls for policy integration were made concerning sustainability issues, EPI was the answer.

With the emergence of the 2030 Agenda and the SDGs as a new global sustainability governance framework, however, there have been signs of conceptual shifts in the sustainability discourse. These affect, among others, the interpretation of policy integration and the orientation of related practices (see also Bornemann \& Christen, 2021). The 2030 Agenda is based on the earlier Millennium Development Goals and on the preceding international sustainability debate. By combining and extending both strands, it forms a powerful overall vision of global sustainable development that aims to address, in an integrated manner, the many challenges facing humanity to ensure economic prosperity, human wellbeing, and the protection of the planet (United Nations, 2015). Integration is consequently a prominent leitmotif of the new Agenda (Nilsson \& Persson, 2017). It emphasises that different issues such as poverty, gender equality, education, and environmental degradation etc. are intertwined and that the 17 SDGs form an indivisible whole' and can only be achieved together. As stated in the 2015 UN General Assembly Declaration, the goals are "integrated and indivisible and balance the three dimensions of sustainable development: the economic, social, and environmental" (United Nations, 2015, p. 1). The strong emphasis on integration is based not least on the insight that the goals of the 2030 Agenda are characterised by numerous contradictions, which have come to the fore and are further exacerbated in the transition from the Millennium Development Goals to the SDGs (Biggeri, Clark, Ferrannini, \& Mauro, 2019). Overall, while the 2030 Agenda is clearly based on an integration concept, it remains rather vague concerning the precise interpretation of the term.

\section{Method: Analysing the Meaning of Policy Integration in the Literature on the $\mathbf{2 0 3 0}$ Agenda}

In the following, we turn to an analysis of how integration is interpreted in the academic literature on the $\mathbf{2 0 3 0}$ Agenda. To reconstruct current interpretations of policy integration in this context, we conducted a review of the relevant literature on the topic focussed on scholarly articles identified through the Scopus database.

The selection of articles proceeded as follows. The search string was composed of three requirements (connected through the operator AND) that the resulting records needed to fulfil: 1) publications including the search terms '2030 Agenda,' 'sustainable development goals' and 'SDG*' (with * indicating truncation to cover all variants), connected through $\mathrm{OR}$, meaning that any of the search terms can be present in the result; 2) publications focussing on the topic of integration, for which a combination of the terms 'integration,' 'coherence,' 'trade-off,' 'synergies' and 'interaction' (including variations) apply, again connected through OR (search string: integrat* OR coheren* OR trade*off* OR synerg* OR interact*); 3) publications with a policy or governance focus, including variations (search sting: policy OR gov$\left.e r n^{*}\right)$, thus excluding analyses that were merely dealing with socio-ecological systems or static analyses. Only publications from the years 2015 to 2020 were included. In terms of document types, we selected articles, book chapters, reviews, editorials, and notes (we excluded entire books, conference papers, conference reviews, and letters). Finally, for practical reasons, only publications in the English language were included. The search resulted in a sample of 1,281 documents.

In a second step, we analysed the publications' abstracts regarding their fit with our research. Many publications used the 2030 Agenda and/or (selected) SDGs merely as a framing of their argumentation or 'window dressing,' rather than substantially analysing them. Others had only a vague understanding of the notion of integration, and some focussed on integration at the societal level, instead of policy integration in a narrower sense (i.e., problems, goals, and means). Such publications were excluded from further analysis, and the remaining sample included 93 records.

In a third step, we qualified and ranked the remaining publications using the Scopus Field-weighted Citation Index to select the most cited and most relevant texts in the integration discourse around the 2030 Agenda. The Scopus Field-weighted Citation Index qualifies a publication's citations in relation to the average citations expected in its field. The index thus accounts for different citation frequencies in different fields and enables a 'field normalisation,' providing a more accurate measure of discourse relevance than a raw citation count. The ranking of our remaining sample revealed great differences in their index value, ranging from 0 (not cited) to 56 (most cited). A large proportion of publications had small values, and 10 articles were yet to be cited. We defined 5 as a cut-off value, which provided us with a sample of 27 publications. A full-text analysis then led us to exclude another five publications that were not relevant for our study, which eventually resulted in a sample of 22 discourse relevant publications that were included in our analysis.

The sample was then analysed using systematic review methods (Petticrew \& Roberts, 2006). Both authors thoroughly read the selected texts and condensed central information in the form of spreadsheets, which were discussed and iteratively refined. The unit of analysis was not the entire publication with its respective analytical or empirical focus, but the underlying (explicit or implicit) understanding of policy integration. We based our analysis on a set of questions to which, arguably, any systematic concept of policy integration must respond (Bornemann, 2014): The first question, 'why to integrate?' is about the reasons underlying and justifying policy integration. The second, 'what to integrate?' refers to a clarification of the objects of policy integration regarding the 2030 Agenda. The third, "how 
to integrate?' relates to the modes of policy integration that are present in the literature about policy integration in the context of 2030 Agenda. In the following section, we present the results from our analysis of the different questions. Table 1 in the Supplementary File provides a synopsis of the key findings by articles.

\section{Results: Reasons, Objects and Modes of Policy Integration for the 2030 Agenda}

\subsection{Reasons for Policy Integration}

Regarding the underlying reasons for policy integration, i.e., the question of why policy integration should take place at all, there is considerable convergence in the literature we analysed. Most generally, policy integration is considered a crucial prerequisite for sustainable development in general, and for the successful implementation of the 2030 Agenda and the SDGs in particular (Biermann et al., 2017; Biggeri et al., 2019, pp. 642; Nilsson, Griggs, \& Visbeck, 2016). Underlying this call for integration is the diagnosis known from policy integration literature that the prevailing pattern of sectoral policymaking and governance has led to an "insufficient understanding of and accounting for trade-offs and synergies across sectors [that] have resulted in incoherent policies, adverse impacts...on other sectors, and ultimately in diverging outcomes and trends across broad objectives for sustainable development" (Le Blanc, 2015, pp. 176-177; see also Liu et al., 2018). Similarly, Boas et al. (2016) write that the problems that are usually related to "different domains-for instance, water, energy and food-[which] are interconnected and can thus not be effectively resolved unless they are addressed as being fully interrelated and interdependent" (Boas et al., 2016, p. 449; see also Collste, Pedercini, \& Cornell, 2017). Stafford-Smith et al. (2017) specify that integration is needed because "uncoordinated action" can "create internal conflicts, such as subsidies for both renewable and non-renewable fuel sources" or lead to "missed synergies," e.g., "targeted investment in renewable energy reduces emissions [that...] could also reduce pollution, improve human health, and increase equality" (Stafford-Smith et al., 2017, p. 912, emphasis added).

While these concerns relate to the more general pattern of fragmented policymaking that has been deemed responsible for unsustainable development, other authors derive the need for integration more directly from the 2030 Agenda and the SDGs themselves. Allen, Metternicht, and Wiedmann (2019, p. 422) argue that the "integrated nature of the SDG targets means that progress towards one target is also linked through complex feedbacks to other targets," which is why "interdependencies between targets [need to be] taken into account in strategy and policy formulation." Taking into account interdependencies between targets serves to exploit synergies or cross-sectoral benefits between goals, as well as to reduce or avoid trade-offs
(Bai et al., 2016; Boas et al., 2016; Liu et al., 2018; Nerini et al., 2019; Nilsson et al., 2018), or even to turn tradeoffs into synergies (Kroll, Warchold, \& Pradhan, 2019; Scherer et al., 2018).

In addition to directly addressing synergies and trade-offs between (sectoral) goals and targets through more integrated policies, a better understanding of the integrated nature of the SDG system is seen as a prerequisite for the meaningful prioritisation of policy activities (Allen et al., 2019; Bai et al., 2016; Kroll et al., 2019; McCollum et al., 2018). Weitz, Carlsen, Nilsson, and Skånberg (2018, p. 531) state that by "considering how a target interacts with another target and how that target, in turn, interacts with other targets, results [in] a more robust basis for priority setting of SDG efforts." This is very much in line with Nilsson et al. (2018, p. 1490) who argue that "systematically focusing the MOI [means of implementation] (finance, technology, capacity building, trade, policy coherence, partnerships, data, monitoring and accountability) on SDG interactions can lead to more integrated decision-making and coherent policy approaches."

Furthermore, some authors argue that policy integration in the context of the 2030 Agenda may also "reveal unrecognized opportunities" (Bai et al., 2016, p. 69) and enhance policy effectiveness not only from an overall system perspective but also from the point of view of individual policymakers:

If they look outside the priorities of their sectoral turf and at how they influence-and are influenced byothers, they are likely to find common interests and (unexpected) alliances and that more integrated policymaking is likely to pay off in terms of more effective development outcomes. (Nilsson et al., 2018, p. 1499)

Thus, greater knowledge about and recognition of SDG interactions drives policymakers toward socially more desirable development pathways (McCollum et al., 2018).

\subsection{Objects of Policy Integration}

As regards the second question on the 'what' of policy integration, the general debate on policy integration has brought up multiple understandings of potential objects of integration, ranging from comprehensive policy domains and sectors to various specific policy elements, such as policy problems, goals or means (Bornemann, 2014, pp. 106-153). The 2030 Agenda prima facie points to policy goals and targets, thus implying an understanding of policy integration as 'goal integration' (Biermann et al., 2017). The emphasis on goals as objects of policy integration however needs to be differentiated further. Whereas some texts in our sample point to the SDGs (Barbier \& Burgess, 2017; Boas et al., 2016; Waage et al., 2015), others emphasise that it is the targets, rather than the goals, which need to 
be integrated (e.g., Allen et al., 2019; Le Blanc, 2015; McCollum et al., 2018; Weitz et al., 2018).

These differences seem to be connected to differing perspectives on where integration is taking place. Some articles analyse the general architecture of the SDGs as an 'indivisible whole' or a system in which all goals are interlinked. As such, the SDG system functions as "an enabler of integration," and "a common benchmark against which development progress can be assessed" (Le Blanc, 2015, pp. 180-182), meaning integration is achieved through goal integration (Biermann et al., 2017). Others, in contrast, focus on the contextual implementation of the SDGs as the process in which integration is to be achieved (Allen, Metternicht, \& Wiedmann, 2018; Bowen et al., 2017; Nilsson et al., 2018; Weitz et al., 2018). The goals and targets are to be integrated into concrete settings, in which their respective relevance and interactions differ. For this reason, any implementation action-and thus any integration effort-has to be context-specific. Waage et al. (2015) further qualify integration of the various SDGs by assigning them to three concentric layers (individual wellbeing, social infrastructure, environmental conditions) to indicate their interlinkage, with each layer being associated with different governance settings.

\subsection{Modes of Policy Integration}

The third question, concerning the 'how' of integration, refers to the mode of policy integration. This is to specify what kind of relationships between different policies or policy objects are promoted or considered adequate in the light of the 2030 Agenda. Although the degree of elaboration varies (with some contributions shifting the specification of the integration mode to the policymaking process itself; see Biermann et al., 2017), the literature broadly converges on a common overarching modal profile of the 2030 Agenda. Based on a number of pairs of opposites to characterise modes of (policy) integration (Bornemann, 2014, pp. 76-105), we observe the following general tendencies.

Firstly, more pronounced than earlier concepts of sustainability, the 2030 Agenda is meant as a comprehensive development agenda for a global society. This feature is emphasised to different degrees in all analysed texts. It goes hand in hand with a far-reaching integration mission and implies an extensive conception of policy integration, most distinctively referred to in Weitz et al.'s (2018) explicit reference to a 'whole-of-government' approach. In other words, every goal should in principle be part and parcel of any policy integration attempt. This does not entail that all goals play, or should play, an equal role, but is to say that no goal can, or should be, excluded from policy integration considerations from the outset. This general tendency, which resonates with the claim that the SDGs are 'indivisible,' holds for most contributions. Some accounts, however, focus their reflections about goal interdependencies and implications for policy integration on thematically more selective 'nexus' problems (Boas et al., 2016; Bowen et al., 2017; Liu et al., 2018; McCollum et al., 2018). While still adhering to the system perspective characteristic of the 2030 Agenda, nexus thinking is a way to 'navigate' through the various interlinkages between the various goals and targets and to find an inroad into the SDG's complexities. Nexus governance thus refers to the consideration and treatment of interactions between two or more problems (and related SDGs) that are usually regarded as separate (Allen et al., 2018; Bowen et al., 2017).

Secondly, there are strong indications in the literature analysed that policy integration in the context of the 2030 Agenda goes beyond a one-sided understanding of integration, as is for example implied by the concept of EPI. Virtually all texts point to 'systemic' (Weitz et al., 2018) interactions between goals and targets, and identify different types of goal interaction that need to be understood and considered in integrated policymaking (e.g., Allen et al., 2019; Kroll et al., 2019; Nilsson et al., 2018; Singh et al., 2018; Weitz et al., 2018). While assessments of the system of goals and targets reveal a broad diversity of different degrees (strong vs. weak; Weitz et al., 2018) and kinds of linkages (reciprocal vs. one-sided; Kroll et al., 2019), the basic tenet of policy integration is that relationships between the SDGs potentially exist. Therefore, as a basic principle, reciprocal relations and interlinkages between goals and targets are to be considered, at least at the level of scientific analysis.

Thirdly, based on a distinction between simply networked and complex forms of policy integration (as measured by the maximum number of relationships that can be established between different integrated policies), we observe policy integration in the context of the 2030 Agenda to be based on a highly multilateral, i.e., complex form of policy integration. The numerous analyses of potential interactions or interdependencies between individual SDGs (e.g., Kroll et al., 2019; Nerini et al., 2019; Singh et al., 2018; Weitz et al., 2018) indicate that a policy system aligned with the SDGs should basically be thought of in terms of a maximally networked structure in which each policy is potentially related to every other. However, some authors expound that the SDG system is unevenly integrated, "an unequally knit network, with some goals being linked to many other goals, while others have fewer links with the rest of the network" (Le Blanc, 2015, p. 178), pointing to the existence of 'nexus' problems, which link SDGs in thematically selective ways and with differing degrees of complexity (Allen et al., 2018; Boas et al., 2016).

Fourthly, referring to the distinction between forms of symmetric and asymmetric policy integration, with the latter assuming a prioritisation of certain policy goals and the former denying the possibility (and desirability) of equal consideration, or a principled balancing of policies, the 2030 Agenda seems to come with another shift. As mentioned, the 2030 Agenda calls for an extensive, reciprocal, and multilateral assessment of 
goal interactions, which may result in the identification of nexus issues, selectively connecting multiple SDGs. While these kinds of interaction analyses are themselves based on the notion of a principled equal weighing of the goals, their results may suggest a prioritisation of goals. In fact, in most of the articles analysed, the identification of priority goals is the purpose of an integrated analysis of SDGs. The aim is to identify those goals or bundles of goals (nexus) that have a central position in the SDGs' network and therefore serve as powerful entry points for governance interventions. Focussing on these allows one to achieve the greatest number of goals possible, or to reap the greatest possible benefit from achieving them (Allen et al., 2019; Barbier \& Burgess, 2017; Biermann et al., 2017; Kroll et al., 2019; Weitz et al., 2018). An exception from this pattern can be found in Waage et al. (2015) who argue that the goals are ordered a priori in terms of their location in the three spheres (well-being, social, environmental). This in turn points to an asymmetrical mode of policy integration, following a logic of goal prioritisation based on their system embedding.

Finally, it is interesting to note that regarding the relationships between goals and targets, most of the analysed texts emphasise that these are positive. In other words, it is not trade-offs and conflict, or neutral relations between the goals, but synergies and co-benefits that are the dominant interaction mode. The prevalence of positive accounts is observable on the empirical level in analyses of the actual relations between the SDGs and targets and their evolution (e.g., Allen et al., 2019; Kroll et al., 2019; Maes, Jones, Toledano, \& Milligan, 2019; Singh et al., 2018; Weitz et al., 2018). It is also a focus on the political-strategic level. For example, Kroll et al. $(2019$, p. 1) suggest setting off a "virtuous cycle of SDG progress" in which trade-offs are transformed into synergies. By looking at successful examples, policymakers are challenged to emulate positive relationships between different SDGs in fields where trade-offs dominate (see also Allen et al., 2019; Boas et al., 2016). Sustainable development, in this perspective, is viewed as a self-reinforcing process that makes strategic use of interlinkages in the socio-ecological system and strives to steer it beneficially.

\section{Discussion: Reconsidering Policy Integration for Sustainability}

Our literature review reveals a considerable convergence in the conceptualisation of policy integration for the 2030 Agenda. Policy integration in the context of the 2030 Agenda refers to the identification of critical points of policy intervention that allow for the greatest achievement of as many SDGs as possible, based on a sophisticated understanding of the interactions between all goals of the SDG system. Policy integration in the context of the 2030 Agenda thus becomes a knowledge-based undertaking of policy priority setting, based on a more or less context-related analysis of the interactions between the elements of a complex target system, which is to provide indications of the most efficient allocation of resources. In the following, we discuss this understanding of policy integration for the 2030 Agenda in relation to the dominant understanding of policy integration for sustainability, i.e., EPI. While there are some similarities, we argue that policy integration for the 2030 Agenda deviates in some key respects from EPI.

Regarding the reasons for policy integration, we first of all note that the more recent discussion on policy integration in the context of the 2030 Agenda is based on different justifications than the one on EPI. The central basis for policy integration in the 2030 Agenda context is the belief that integration can make policymaking more rational. Not only can synergies be realised through policy integration, but also contradictions between policies can be eliminated. With the help of focussed interventions in relation to critical goals or sets of goals, the allocation of policy resources can be optimised in a way that the greatest impact on sustainable development as a whole can be achieved. While this may evoke rationalistic ideas of policy integration, which also characterise large parts of the general discussion on policy integration, EPI's mission is different. EPI is concerned with the elimination of a non-rational pattern of policymaking, too, in the sense of realising effectiveness and efficiency gains by considering environmental concerns at the early stages of policy design (as opposed to, for example, end-of-pipe measures). However, some interpretations of EPI articulate the idea of a fundamental shift in the normative basis of policymaking, namely the prioritisation of environmental concerns over sectoral goals (Lafferty \& Hovden, 2003). Here, policy integration is no longer functionally geared to the achievement of specific goals, but rather to their re-orientation. Viewed against this far-reaching normative claim of EPI, ideas of policy integration in the context of the 2030 Agenda are more modest in that they are directed at the (most efficient and effective) realisation of an existing system of objectives.

Considering the objects of policy integration, i.e., the findings regarding the question 'what to integrate,' we note a continuity between EPI and policy integration for the 2030 Agenda. Both concepts emphasise goals as integration objects but tend to neglect other conceivable objects of integration, such as policy problems or policy instruments (Bornemann, 2014; Briassoulis, 2005). $E P I$ is about the integration of environmental goals into the normative system and structure of particular policy fields (such as agricultural policy), whereas policy integration for the 2030 Agenda is concerned with the relations between individual SDGs and their associated targets. This conceptual focus makes integration a normative endeavour, but overlooks other (cognitive and instrumental) aspects that present both opportunities and challenges for integration.

As regards modes of policy integration, we again find some crucial differences. First, while EPI is based 
on an understanding of integration that is specifically oriented towards the achievement of environmental goals, but disregards the broader normative implications of sustainable development, policy integration for the 2030 Agenda implies an extensive policy integration understanding. This is demonstrated by the fact that the contributions reviewed cover the entire spectrum of sustainability by referring to all goals of a broadly defined universe of goals of political action, i.e., the SDGs. Given its comprehensiveness, policy integration for the 2030 Agenda does justice to the normative breadth of the sustainability idea, which has already been enshrined in the Brundtland Report, but which has at times been overshadowed by selective interpretations focusing on specific economic, social or, in the case of EPI, environmental dimensions of the concept.

The turning away from selective understandings of policy integration also comes to bear in another mode of policy integration referring to the direction of integration. In contrast to EPI, policy integration for the 2030 Agenda cannot be conceived in terms of a one-sided activity aimed at incorporating environmental goals into sectoral policies. Given the comprehensiveness and complexity of the SDG system, an adequate concept of policy integration involves the consideration of reciprocal relationships between goals, which are more or less linked to specific policy sectors (Nilsson \& Persson, 2017). Moreover, while EPI involves a rather simple form of policy integration in that additional environmental concerns are only related to particular sector policies, policy integration for the 2030 Agenda involves a high level of integration complexity. Consequently, many more (sectoral or overarching) goals are of importance, and these goals are interrelated in every conceivable way.

While extensity, reciprocity, and complexity mark clear structural differences between EPI and policy integration for the 2030 Agenda, both approaches converge to some extent concerning the weighting of goals. Both EPI and (large parts of) the literature on the 2030 Agenda-related policy integration have their vanishing points in a prioritisation of goals, which distinguishes them from symmetric approaches to policy integration aiming at balancing goals (Bornemann, 2014, pp. 287-288). However, EPI assumes a normatively founded principle of prioritising environmental goals over other sectoral goals, whereas the prioritisation logic of policy integration for the 2030 Agenda is more functionalist. It serves to identify critical leverage goals whose implementation promises the greatest impact on the goal system as a whole. From a historical perspective, this change in the logic of prioritisation corresponds to a more fundamental change in the understanding of sustainability: From a rule-oriented and principle-based (ecological) interpretation of sustainability, represented by EPI, to a goal-oriented, evidence-based and comprehensive understanding of sustainable development.

This change has fundamental implications for governance. One of them concerns the relationship between science and politics in the context of sustainability governance. In the context of EPI, the prioritisation of environmental goals is based on a politically legitimised rule supported by principle-based and factual scientific considerations about the centrality of ecological systems. However, in the context of policy integration in the 2030 Agenda, science seems to move to a more central governance position. Although not all of the analysed texts explicitly refer to who is involved in integrative policymaking, a majority of them give scientific experts the role of mapping and evaluating the interactions between the SDGs to provide evidence about which are the most important goals within the system, and which should be prioritised in policymaking and implementation. In other words, scientific experts provide evidence of and for reasonable goal prioritisation. This comes with considerable technocratic implications in that policymakers appear as implementers of scientific knowledge. As a result, policy integration seemingly becomes the technocratic endeavour that some have always believed it to be: An effort to tackle fundamental political and value conflicts through improved knowledge of how to optimise the realisation of multiple goals by creating a smoothly functioning and seamless policy system that creates and perpetuates societal progress (Allen et al., 2018; Biggeri et al., 2019; Collste et al., 2017; McCollum et al., 2018).

Considering these technocratic connotations, we should, however, bear in mind that integration in the context of the 2030 Agenda refers to a system of integration objects, i.e., the SDGs and related targets, which is essentially political in nature. As a number of authors emphasise, the SDGs are the result of a political decision process involving national governments and multiple political actors from various contexts (Biermann et al., 2017; Le Blanc, 2015). The agenda as a whole therefore represents a compromise of different political ideas and interests. This explains the inconsistencies and contradictions within the resulting system of objectives, i.e., the trade-offs between objectives introduced by different interest coalitions. This in turn presents the supposedly central role of science in governance in a slightly different light. Rather than setting targets, science is concerned with analysing the possible interactions between the elements of a politically defined target system. The role of science is not to 'speak truth to power,' but rather to analyse and interpret a politically constructed framework of goals regarding its integrative implications. The SDGs represent a politically defined, comprehensive, and complex system of objectives which must be scientifically researched and understood in order to identify knowledge about systemic points of intervention for integrative policy designs.

\section{Conclusion}

In this article, we analysed the notion of policy integration in the context of the 2030 Agenda and the SDGs against the background of the historical sustainability 
discourse. We found that the current notion of policy integration departs significantly from the EPI concept which has long dominated the debate on sustainable development. Turning away from the rather onedirectional and selective EPI approach, the 2030 Agenda promotes an encompassing, reciprocal, and complex integration approach. In contrast to the principle-based and rule-oriented prioritisation approach of EPI, policy integration in the context of the 2030 Agenda is based on a functionalist logic of prioritisation, which-starting from an evidence-based analysis of goal interactionsidentifies priority goals as leverage points for improving the overall system. The role of evidence and knowledge is paramount because they provide the basis for managing and optimising the complex relations between goals and targets. In addition, the strong emphasis on synergies and co-benefits, and the idea that conflicts and trade-offs can be overcome, adds to the managerial account of sustainable development. Beyond that technocratic outlook, one should however not forget that the 2030 Agenda and the SDGs are a political goals system, representing a compromise between the UN member states which was made in a specific historical situation. It is in the nature of the 'governing through goals' approach (Kanie et al., 2019) that the political intervention is made on the level of objectives, leaving the further steps, in particular implementation, to the subsequent political process. Consequently, we can understand the 2030 Agenda and the SDGs to promote a specific interpretation of the (policy) integration challenges posed by sustainability.

The 2030 Agenda and its concept of policy integration raise an array of questions for future research. Next to further analyses of SDG interactions in specific contexts with the aim of providing scientific support for their practical implementation, we see three main research perspectives for policy integration in the context of the 2030 Agenda. Firstly, as a continuation of existing empirical work on the implementation of the 2030 Agenda in general (Allen et al., 2018) and on policy integration in particular (Tosun \& Leininger, 2017), research should focus on whether and how the specific form of policy integration of the 2030 Agenda actually becomes relevant in political practice. Does its implementation lead to new governance arrangements and practices? Do these differ from the earlier implementation of EPI? How do interaction analyses and goal prioritisation look like on the ground? Are there new forms of integration-oriented cooperation between science and politics? Secondly, a question arises regarding the political-institutional prerequisites, the conditions or mechanisms that enable or hinder the practical implementation of policy integration for the 2030 Agenda: Under which conditions is policy integration of the SDGs successfully implemented? Finally, the empirical effects of new arrangements and practices of policy integration should be examined: To what extent does a political practice of policy integration that is consistent with the 2030 Agenda lead to inte- grated steering impulses and ultimately to an integrated sustainable development of society? These questions are paramount for any research aiming to promote the achievement of the 2030 Agenda and the SDGs.

\section{Acknowledgments}

We thank three anonymous reviewers and the Academic Editors of this thematic issue for their constructive comments, which have significantly improved the article. Basil Bornemann's contribution to this article was made as part of the project 'The Sustainabilization of the State,' supported by the Swiss National Science Foundation under grant number 178810 .

\section{Conflict of Interests}

The authors declare no conflict of interests.

\section{Supplementary Material}

Supplementary material for this article is available online in the format provided by the authors (unedited).

\section{References}

6, P., Leat, D., Seltzer, K., \& Stoker, G. (2002). Towards holistic governance: The new reform agenda. Basingstoke: Palgrave.

Adelle, C., \& Russel, D. (2013). Climate policy integration: A case of déjà vu? Environmental Policy and Governance, 23(1), 1-12. https://doi.org/10.1002/ eet.1601

Allen, C., Metternicht, G., \& Wiedmann, T. (2018). Initial progress in implementing the Sustainable Development Goals (SDGs): A review of evidence from countries. Sustainability Science, 13, 1453-1467. https:// doi.org/10.1007/s11625-018-0572-3

Allen, C., Metternicht, G., \& Wiedmann, T. (2019). Prioritising SDG targets: Assessing baselines, gaps and interlinkages. Sustainability Science, 14(2), 421-438. https://doi.org/10.1007/s11625-018-0596-8

Bai, X., Surveyer, A., Elmqvist, T., Gatzweiler, F., Güneralp, B., Parnell, S., . . . Webb, R. (2016). Defining and advancing a systems approach for sustainable cities. Current Opinion in Environmental Sustainability, 23, 69-78. https://doi.org/10.1016/j.cosust.2016. 11.010

Barbier, E. B., \& Burgess, J. C. (2017). The sustainable development goals and the systems approach to sustainability. Economics, 11. https://doi.org/10.5018/ economics-ejournal.ja.2017-28

Biermann, F., Kanie, N., \& Kim, R. E. (2017). Global governance by goal-setting: The novel approach of the UN Sustainable Development Goals. Current Opinion in Environmental Sustainability, 26/27, 26-31. https:// doi.org/10.1016/j.cosust.2017.01.010

Biggeri, M., Clark, D., Ferrannini, A., \& Mauro, V. (2019). 
Tracking the SDGs in an 'integrated' manner: A proposal for a new index to capture synergies and tradeoffs between and within goals. World Development, 122, 628-647, https://doi.org/10.1016/j.worlddev. 2019.05.022

Boas, I., Biermann, F., \& Kanie, N. (2016). Cross-sectoral strategies in global sustainability governance: Towards a nexus approach. International Environmental Agreements: Politics, Law and Economics, 16(3), 449-464. https://doi.org/10.1007/s10784016-9321-1

Bogdanor, V. (Ed.). (2005). Joined-up government. Oxford: Oxford University Press.

Bornemann, B. (2014). Policy-Integration und Nachhaltigkeit: Integrative Politik in der Nachhaltigkeitsstrategie der deutschen Bundesregierung [Policy integration and sustainability: Integrative policymaking in the sustainability strategy of the German Federal Government] (2nd ed.). Wiesbaden: Springer VS.

Bornemann, B. (2016). Integrative political strategies: Conceptualizing and analyzing a new type of policy field. European Policy Analysis, 2(1), 168-195. https://doi.org/10.18278/epa.2.1.10

Bornemann, B., \& Christen, M. (2021). The potential of sustainability governance arrangements to implement the 2030 Agenda: Insights from Swiss cantons. Politics and Governance, 9(1), 187-199.

Bowen, K. J., Cradock-Henry, N. A., Koch, F., Patterson, J., Häyhä, T., Vogt, J., \& Barbi, F. (2017). Implementing the "Sustainable Development Goals": Towards addressing three key governance challenges: Collective action, trade-offs, and accountability. Current Opinion in Environmental Sustainability, 26/27, 90-96. https://doi.org/10.1016/j.cosust. 2017.05.002

Brand, K.-W. (Ed.). (2017). Die sozial-ökologische Transformation der Welt: Ein Handbuch [The socialecological transformation of the world: A handbook]. Frankfurt: Campus Frankfurt.

Briassoulis, H. (Ed.). (2005). Policy integration for complex environmental problems: The example of Mediterranean desertification. Burlington, VT: Ashgate.

Burstein, P. (1991). Policy domains: Organization, culture, and policy outcomes. Annual Review of Sociology, 17(1), 327-350. https://doi.org/10.1146/annurev.so. 17.080191.001551

Candel, J., \& Biesbroek, R. (2016). Toward a processual understanding of policy integration. Policy Sciences, 49, 1-21. https://doi.org/10.1007/s11077016-9248-y

Casado-Asensio, J., \& Steurer, R. (2014). Integrated strategies on sustainable development, climate change mitigation and adaptation in Western Europe: Communication rather than coordination. Journal of Public Policy, 34(3), 437-473. https://doi.org/ $10.1017 /$ S0143814X13000287
Cejudo, G. M., \& Michel, C. L. (2017). Addressing fragmented government action: Coordination, coherence, and integration. Policy Sciences, 14(1). https:// doi.org/10.1007/s11077-017-9281-5

Christensen, T., \& Lægreid, P. (2007). The whole-ofgovernment approach to public sector reform. Public Administration Review, 67(6), 1059-1066. https:// doi.org/10.1111/j.1540-6210.2007.00797.x

Collste, D., Pedercini, M., \& Cornell, S. (2017). Policy coherence to achieve the SDGs: Using integrated simulation models to assess effective policies. Sustainability Science, 12, 921-931. https://doi.org/ 10.1007/s11625-017-0457-x

Dryzek, J. S. (2013). The politics of the Earth: Environmental discourses (3rd ed.). Oxford: Oxford University Press.

Jacobs, M. (1999). Sustainable development as a contested concept. In A. Dobson (Ed.), Fairness and futurity: Essays on environmental sustainability and social justice (pp. 21-45). Oxford: Oxford University Press.

Jochim, A. E., \& May, P. J. (2010). Beyond subsystems: Policy regimes and governance. Policy Studies Journal, 38(2), 303-327. https://doi.org/10.1111/j.15410072.2010.00363.x

Jordan, A., \& Lenschow, A. (2008). Environmental policy integration: An innovation in environmental policy? In A. Jordan \& A. Lenschow (Eds.), Innovation in environmental policy? Integrating the environment for sustainability (pp. 313-341). Cheltenham and Northampton, MA: Edward Elgar Publishing.

Jordan, A., \& Lenschow, A. (2010). Environmental policy integration: A state of the art review. Environmental Policy and Governance, 20(3), 147-158. https:// doi.org/10.1002/eet.539

Kanie, N., \& Biermann, F. (Eds.). (2017). Earth system governance: Governing through goals: Sustainable Development Goals as governance innovation. Cumberland: MIT Press.

Kanie, N., Griggs, D., Young, O., Waddell, S., Shrivastava, P., Haas, P. M., . . . Körösi, C. (2019). Rules to goals: Emergence of new governance strategies for sustainable development. Sustainability Science, 14(6), 1745-1749. https://doi.org/10.1007/s11625019-00729-1

Kroll, C., Warchold, A., \& Pradhan, P. (2019). Sustainable Development Goals (SDGs): Are we successful in turning trade-offs into synergies? Palgrave Communications, 5(1). https://doi.org/10.1057/s41599-0190335-5

Lafferty, W. M., \& Hovden, E. (2003). Environmental policy integration: Towards an analytical framework. Environmental Politics, 12(3), 1-22.

Langford, M. (2016). Lost in transformation? The politics of the Sustainable Development Goals. Ethics \& International Affairs, 30(2), 167-176. https://doi.org/ $10.1017 /$ S0892679416000058

Le Blanc, D. (2015). Towards integration at last? The Sustainable Development Goals as a network of targets. 
Sustainable Development, 23(3), 176-187. https:// doi.org/10.1002/sd.1582

Lenschow, A. (Ed.). (2002a). Environmental policy integration: Greening sectoral policies in Europe. London and Sterling, VA: Earthscan.

Lenschow, A. (2002b). Greening the European Union: An introduction. In A. Lenschow (Ed.), Environmental policy integration: Greening sectoral policies in Europe (pp. 3-21). London and Sterling, VA: Earthscan.

Liberatore, A. (1997). The integration of sustainable development objectives into EU policymaking. In S. Baker, M. Kousis, D. Richardson, \& S. Young (Eds.), Global environmental change series: The politics of sustainable development: Theory, policy and practice within the European Union (pp. 107-126). London and New York, NY: Routledge.

Liu, J., Hull, V., Godfray, H., Tilman, D., Gleick, P., Hoff, H., . . . Li, S. (2018). Nexus approaches to global sustainable development. Nature Sustainability, 1(9), 466-476. https://doi.org/10.1038/s41893-0180135-8

Maes, M., Jones, K., Toledano, M., \& Milligan, B. (2019). Mapping synergies and trade-offs between urban ecosystems and the sustainable development goals. Environmental Science \& Policy, 93, 181-188. https:// doi.org/10.1016/j.envsci.2018.12.010

McCollum, D. L., Echeverri, L. G., Busch, S., Pachauri, S., Parkinson, S., Rogelj, J., . . . Riahi, K. (2018). Connecting the sustainable development goals by their energy inter-linkages. Environmental Research Letters, 13(3). https://doi.org/10.1088/1748-9326/ aaafe3

Meadowcroft, J. (2007). National sustainable development strategies: Features, challenges and reflexivity. European Environment, 17, 152-163.

Meadowcroft, J. (2013). Sustainable development. In M. Bevir (Ed.), The SAGE handbook of governance (pp. 535-551). London: Sage.

Meadowcroft, J., Banister, D., Holden, E., Langhelle, O., Linnerud, K., \& Gilpin, G. (Eds.). (2019). What next for sustainable development? Our common future at thirty. Cheltenham and Northampton, MA: Edward Elgar Publishing.

Nerini, F., Sovacool, B., Hughes, N. Cozzi, L., Cosgrave, E., Howells, M., . . Milligan, B. (2019). Connecting climate action with other Sustainable Development Goals. Nature Sustainability, 2, 674-680. https://doi. org/10.1038/s41893-019-0334-y

Nilsson, M., Chisholm, E., Griggs, D., Howden-Chapman, P., McCollum, D., Messerli, P., . . . Stafford-Smith, M. (2018). Mapping interactions between the sustainable development goals: Lessons learned and ways forward. Sustainability Science, 13(6), 1489-1503. https://doi.org/10.1007/s11625-018-0604-z

Nilsson, M., \& Eckerberg, K. (Eds.). (2007). Environmental policy integration in practice: Shaping institutions for learning. London: Earthscan.
Nilsson, M., Eckerberg, K., Hagberg, L., Swartling, Å. G., \& Söderberg, C. (2007). Policy framing and EPI in energy and agriculture. In M. Nilsson \& K. Eckerberg (Eds.), Environmental policy integration in practice: Shaping institutions for learning (pp. 85-110). London: Earthscan.

Nilsson, M., Griggs, D., \& Visbeck, M. (2016). Policy: Map the interactions between Sustainable Development Goals. Nature, 534(7607), 320-322. https://doi: 10.1038/534320a

Nilsson, M., Pallemaerts, M., \& Homeyer, I. v. (2009). International regimes and environmental policy integration: Introducing the special issue. International Environmental Agreements: Politics, Law and Economics, 9(4), 337-350. https://doi.org/10.1007/ s10784-009-9108-8

Nilsson, M., \& Persson, Å. (2017). Policy note: Lessons from environmental policy integration for the implementation of the 2030 Agenda. Environmental Science \& Policy, 78, 36-39. https://doi.org/10.1016/ j.envsci.2017.09.003

Nordbeck, R., \& Steurer, R. (2015). Multi-sectoral strategies as dead ends of policy integration: Lessons to be learned from sustainable development. Environment and Planning C: Government and Policy. Advance online publication. https://doi.org/ 10.1177/0263774X15614696

OECD. (2018). Policy coherence for sustainable development 2018. Paris: OECD. https://doi.org/10.1787/ 9789264301061-en

Peters, B. G. (1998). Managing horizontal government: The politics of co-ordination. Public Administration, 76(2), 295-311.

Petticrew, M., \& Roberts, H. (2006). Systematic reviews in the social sciences: A practical guide. Malden, MA: Blackwell. https://doi.org/10.1002/9780470754887

Purvis, B., Mao, Y., \& Robinson, D. (2019). Three pillars of sustainability: In search of conceptual origins. Sustainability Science, 14(3), 681-695. https://doi.org/ 10.1007/s11625-018-0627-5

Rayner, J., \& Howlett, M. (2009). Introduction: Understanding integrated policy strategies and their evolution. Policy and Society, 28(2), 99-109. https://doi. org/10.1016/j.polsoc.2009.05.001

Scherer, L., Behrens, P., de Koning, A., Heijungs, R., Sprecher, B., \& Tukker, A. (2018). Trade-offs between social and environmental Sustainable Development Goals. Environmental Science \& Policy, 90, 65-72, https://doi.org/10.1016/j.envsci.2018.10.002

Singh, G. G., Cisneros-Montemayor, A. M., Swartz, W., Cheung, W., Guy, J. A., Kenny, T.-A., . . Ota, Y. (2018). $A$ rapid assessment of co-benefits and trade-offs among Sustainable Development Goals. Marine Policy, 93, 223-231. https://doi.org/10.1016/j.marpol. 2017.05.030

Stafford-Smith, M., Griggs, D., Gaffney, O., Ullah, F., Reyers, B., Kanie, N., . . . O'Connell, D. (2017). Integration: The key to implementing the Sustainable Devel- 
opment Goals. Sustainability Science, 12(6), 911-919. https://doi.org/10.1007/s11625-016-0383-3

Steurer, R. (2008). Sustainable development strategies. In A. Jordan \& A. Lenschow (Eds.), Innovation in environmental policy? Integrating the environment for sustainability (pp. 93-113). Cheltenham and Northampton, MA: Edward Elgar Publishing.

Steurer, R. (2010). Sustainable development as a governance reform agenda: Principles and challenges. In R. Steurer \& R. Trattnigg (Eds.), Nachhaltigkeit regieren: Eine Bilanz zu Governance-Prinzipien und -Praktiken [Governing sustainability: A review of governance principles and practices] (pp. 33-52). Munich: Oekom Verlag.

Termeer, C. J. A. M., Dewulf, A., Breeman, G., \& Stiller, S. J. (2015). Governance capabilities for dealing wisely with wicked problems. Administration \& Society, 47(6), 680-710. https://doi.org/10.1177/ 0095399712469195

Tosun, J., \& Lang, A. (2017). Policy integration: Mapping the different concepts. Policy Studies, 38(6), 553-570. https://doi.org/10.1080/01442872.2017.1339239

Tosun, J., \& Leininger, J. (2017). Governing the inter- linkages between the Sustainable Development Goals: Approaches to attain policy integration. Global Challenges, 1(9). https://doi.org/10.1002/gch2. 201700036

Underdal, A. (1980). Integrated marine policy: What? Why? How? Marine Policy, 4(3), 159-169.

United Nations. (2015). Transforming our world: The 2030 agenda for sustainable development. New York, NY: United Nations.

Waage, J., Yap, C., Bell, S., Levy, C., Mace, G., Pegram, T., ... Poole, N. (2015). Governing the UN sustainable development goals: Interactions, infrastructures, and institutions. The Lancet Global Health, 3(5), e251-e252. https://doi.org/10.1016/S2214$109 \times(15) 70112-9$

WCED. (1987). Our common future. Oxford: Oxford University Press.

Weitz, N., Carlsen, H., Nilsson, M., \& Skånberg, K. (2018). Towards systemic and contextual priority setting for implementing the 2030 agenda. Sustainability Science, 13(2), 531-548. https://doi.org/10.1007/ s11625-017-0470-0

\section{About the Authors}

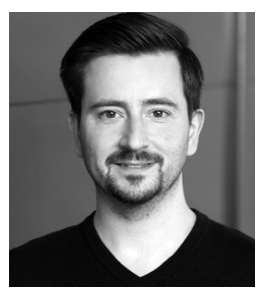

Basil Bornemann is a Postdoctoral Researcher and Lecturer at the Sustainability Research Group, University of Basel. He has an interdisciplinary study background in environmental sciences and holds a doctoral degree in political science. His research focusses on sustainability-oriented governance transformations and their democratic implications in various areas such as energy and food. At present, he is involved in a research project on the sustainabilisation of the state funded by the Swiss National Science Foundation (SNSF).

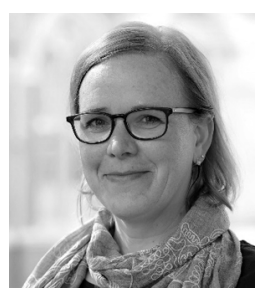

Sabine Weiland is Associate Professor of Political Science at Lille Catholic University, affiliated with the European School of Political and Social Sciences (ESPOL). She is the Director of the ESPOL-LAB Research Centre for European and International Politics. Her research focusses on food politics, environmental politics, sustainable development and transformation of society, reflexive governance, and the role of knowledge in political processes. She analyses issues of integration and reflexivity in the SDGs also in a current book project. 